\title{
O pensamento de Celso Furtado e a construção de um projeto nacional
}

\author{
Carlos Evangelista Veriano* \\ Rafael Pacheco Mourão**
}

\begin{abstract}
Resumo
O presente artigo discute o pensamento de Celso Furtado tendo por tema central a defesa de que há em sua obra um projeto nacional para o Brasil. Pretende-se destacar que esse projeto nacional extrapola a diretiva do viés econômico e contempla também os aspectos políticos, sociais e culturais, ou seja, que propõe "desenvolvimento" no rigor da definição furtadiana, de modo que o mesmo desaguaria na construção de uma Nação republicana e democrática, economicamente forte e com equidade social.
\end{abstract}

Palavras-chave: Celso Furtado; Projeto nacional; Desenvolvimento; Democracia; Nação.

\begin{abstract}
Em meio milênio de história, partindo de uma constelação de feitorias, de populações indígenas desgarradas, de escravos transplantados de outro continente, de aventureiros europeus e asiáticos em busca de um destino melhor, chegamos a um povo de extraordinária polivalência cultural, um país sem paralelo pela vastidão territorial e homogeneidade lingüística e religiosa. Mas nos falta a experiência de provas cruciais, como as que conheceram outros povos cuja sobrevivência chegou a estar ameaçada. E nos falta também um verdadeiro conhecimento de nossas possibilidades, e principalmente de nossas fraquezas. Mas não ignoramos que o tempo histórico se acelera, e que a contagem desse tempo se faz contra nós. Trata-se de saber se teremos um futuro como nação que conta na construção do devenir humano. Ou se prevalecerão as forças que se empenham em interromper o nosso processo histórico de formação de um Estado-nação.
\end{abstract}

Celso Furtado, O fator político na formação nacional, 2000.

\footnotetext{
* Mestre em História pela Universidade Estadual de Campinas (UNICAMP). Professor da Pontifícia Universidade Católica de Minas Gerais (PUC Minas).

** Bacharel Licenciado em História pela Pontifícia Universidade Católica de Minas Gerais (PUC Minas). Funcionário do Centro de Memória e de Pesquisa Histórica da PUC Minas.
} 


\section{Introdução}

Celso Monteiro Furtado $^{1}$ foi o grande economista da corrente desenvolvimentista nacionalista e um dos mais destacados intelectuais do país ao longo do século XX. ${ }^{2}$ Como afirma Francisco de Oliveira, sua obra se transformou em uma representação da realidade, formatando políticas e influenciando gerações, destacando que "a vasta, abrangente e diversificada obra intelectual de Celso Furtado representa um marco na história e produção das ciências sociais à escala mundial.” (1983, p. 7).

Tendo uma vida acadêmica memorável, com doutorado em Paris, trabalhou na CEPAL, em Santiago, sobre a chefia de Raúl Prebisch. Chefiou em 1954 e 1955 o Grupo Misto CEPAL-BNDES, onde elaborou um plano de desenvolvimento para o período de 1955-1962; liderou a formação do Clube dos Economistas e da Revista Econômica Brasileira - que tinham como objetivo primordial contribuir para consolidação de uma base ideológica para o projeto desenvolvimentista nos debates sobre o direcionamento econômico no Brasil. Ocupou a diretoria especial do BNDE, onde elaborou e chefiou o projeto da SUDENE. Por fim, no governo João Goulart, participou do planejamento nacional, onde ocupou o cargo de Ministro Extraordinário de Planejamento, até ser exilado em 1964 e ter cassado os seus direitos políticos por dez anos.

Realizou um refinamento, aplicação e divulgação do pensamento estruturalista, sendo responsável por consolidar entre os desenvolvimentistas nacionalistas brasileiros um entendimento minimamente homogêneo da problemática do subdesenvolvimento do país - provendo-os com uma bagagem teórica para os debates concernentes ao assunto.

Dotado de uma formação muito eclética ${ }^{3}$, pode-se perceber a influência de Karl Mannheim no que tange a organização e planejamento ${ }^{4}$, tendo sua trajetória pautada no

\footnotetext{
${ }^{1}$ Sobre sua trajetória ver Aspásia Camargo e Maria Andréa Loyola, Celso Furtado entrevistado por Aspásia Camargo e Maria Andréa Loyola (2002); e Revista do Instituto Humanitas (UNISINOS), Edição 317, de novembro de 2009.

${ }^{2}$ Maria da Conceição Tavares afirma que Furtado é muito mais que um economista; é um pensador brasileiro. Já Francisco de Oliveira (1983) afirma que Celso Furtado é o demiurgo do Brasil.

3 Francisco de Oliveira (1983, p. 26) coloca que “[...] seus elementos são ecléticos, vindos principalmente de uma fusão histórica - imposta mesmo pelo fato de que as economias e sociedades latino-americanas não haviam nascido ontem - com elementos teóricos-instrumentais keynesianos."

${ }^{4}$ Em entrevista a Aspásia Camargo e Maria Andréa Loyola (2002, p. 14), Furtado afirma que foi “[...] influenciado especialmente por Karl Mannheim”, destacando a importância de Ideologia e Utopia à sua visão acerca do planejamento e racionalidade. Furtado (1983, p. 35) ainda acrescenta que "[...] com a leitura do livro de Mannheim, Man and Society in Age of Reconstruction [...], o planejamento foi para mim uma técnica social de importância muito maior, a qual permitiria elevar o nível de racionalidade das decisões que comandam complexos processos sociais [...]."
} 
estruturalismo de Prebisch, participando, notavelmente, da concepção das bases da teoria estruturalista do desenvolvimento econômico. De maneira que reformulou teses cepalinas e deu-lhes substância, atacando as políticas econômicas liberais e propondo medidas alternativas de cunho desenvolvimentista. Além de estruturalista, Furtado era também um keynesiano ${ }^{5}$ (que se estabelece analiticamente mais como uma derivação de análise macroeconômica ${ }^{6}$ ) - "Seu estruturalismo o orientou na proposta de subordinação da política monetária à política de desenvolvimento e na proposta de planejamento e de intervenção do Estado em suporte à industrialização." (BIELSCHOWSKY, 2000, p. $148)^{7}$

Furtado construiu uma extensa obra que tem por cerne a problemática desenvolvimento/subdesenvolvimento, de maneira que essa se desdobra em vários âmbitos. Assim, o intento desse trabalho será expor o projeto nacional construído por Furtado, demonstrando que, a partir do norte de sua problemática, o autor traçou um projeto que transcende o plano meramente econômico. Nessa perspectiva percebe-se em Furtado a construção diretiva para a "Nação", de crescimento econômico permanente e sustentável, com cunho social, cultural e político muito forte e bem delimitado, ou melhor, um projeto de desenvolvimento que incorpora ao aspecto econômico, o caráter político, social, cultural e ético, pelo surgimento de uma autonomia nacional.

O presente trabalho está estruturado em sete partes. A primeira trata da centralidade da temática de Celso Furtado, bem como do diagnóstico do caso brasileiro, o ponto de partida de elaboração de seu projeto para o Brasil. A segunda enfoca a densidade prática, de ação, existente em sua obra. A terceira expõe a primazia do projeto furtadiano, dando ênfase nos pontos que o diferenciam dos projetos até então construídos. Já a quarta apresenta os papeis da industrialização, do Estado, do planejamento e do desenvolvimento para Furtado. A quinta enfoca os problemas

\footnotetext{
${ }^{5}$ Contudo, para Roy Gilbert (1984, p. 573) "Furtado vai além de Keynes [...] ao frisar, na sua teoria, a importância da mudança tecnológica, tratando as inovações nesta área como a fonte do desenvolvimento." Gilbert ainda destaca seu tratamento realista e pouco utópico desta questão da tecnologia. Outro ponto de relevo no pensamento de Furtado, é que o planejamento estratégico para além de ter uma função anticíclica - de estabilização como propõe Keynes -, contraposto ao automatismo de mercado, é necessário para criar uma racionalidade publica para o desenvolvimento.
}

${ }^{6}$ A análise macroeconômica centra-se no estudo do comportamento agregado de uma economia, portanto, liga-se ao funcionamento do sistema econômico como um todo, especialmente as variações dos produtos, nível geral de preços, nível de emprego, geração de renda, uso de recursos, taxa de juros e balanço de pagamentos. Os objetivos da macroeconomia são essencialmente: o crescimento da economia, o pleno emprego, a estabilidade de preços e o controle inflacionário.

${ }^{7}$ Acerca de sua formação intelectual ver texto Auto-retrato Intelectual (FURTADO; OLIVEIRA, 1983, p. 30-41). 
centrais do caso brasileiro e coloca as respostas elaboradas pelo autor, sobretudo, o aprofundamento democrático, as reformas de base, a mudança social, renovação e inovação tecnológica. A sexta parte expõe a rigor as bases e diretivas do projeto de aspecto social-democrata que aspira o Estado de Bem-Estar Social que comparece na obra do autor. Por fim tece-se uma breve análise do que é proposto pelo projeto furtadiano e o caminho trilhado pelo Brasil nos últimos anos.

\section{Desenvolvimento e subdesenvolvimento}

Segundo Furtado (2000a), os aspectos que dimensionam, a princípio, o conceito de desenvolvimento, são explicitados da seguinte forma: 1. produção, técnica, trabalho; 2. satisfação das necessidades humanas; sendo que estas se desdobram em: a) incremento da eficácia do sistema social de produção; b) satisfação de necessidades elementares da população; c) consecução de objetivos a que almejam grupos dominantes na utilização de recursos - “[...] assim, a concepção de desenvolvimento de uma sociedade não é alheia à sua estrutura social, e tampouco à formulação de uma política de desenvolvimento [...]." (FURTADO, 1965, p. 53) A própria concepção de desenvolvimento para Furtado já se configura no ponto de partida de seu projeto nacional, já que a amplitude da definição de "desenvolvimento", têm para ele uma diretiva global - econômico, político, social e cultural. De modo que o autor conceitua desenvolvimento como "[...] um processo de transformação que engloba o conjunto de uma sociedade" (2000a, p. 41) que é estruturado ao longo de um processo de comportamento racional, de ação programada e de ação técnica. Trata-se de uma ação de "planejamento integral", ou melhor, planejamento global da economia e, respectivamente, da sociedade.

O desenvolvimento, a demais de ser o fenômeno de aumento de produtividade do fator do trabalho que interessa ao economista, é um processo de adaptação das estruturas sociais a um horizonte em expansão de possibilidades abertas ao homem. As duas dimensões - a econômica e a cultural - não podem ser capitadas senão em conjunto [...] - estrutura da população, hábitos dos consumidores, quadro institucional, etc. [...] Em síntese: o desenvolvimento não é uma simples questão de aumento de oferta de bens ou de acumulação de capital, possui ele um sentido, é um conjunto de respostas a um projeto de autotransformação de uma coletividade humana. (FURTADO, 1969, p. 18-19) 
Segundo Vera Cepêda,

[...] o desenvolvimento é, para Furtado, a única possibilidade de garantir a humanização da vida da maioria dos brasileiros. Está em jogo, para ele, mais do que o problema de o país atingir os patamares de riqueza baseados em índices formais. Sua preocupação é com a transformação global da sociedade, com a incorporação de padrões institucionais, culturais e econômicos que nos aproximem da concepção de modernidade. (CEPÊDA, 2001, p. 182)

Nesse caso, ele caracteriza o subdesenvolvimento com condição periférica, correspondente à existência de uma estrutura econômica heterogênea na periferia dedicada essencialmente a atividades de exportação e a um extenso setor de subsistência que opera em níveis de produtividade muito baixo. O subdesenvolvimento seria, portanto, um subproduto desse desenvolvimento - numa abordagem que se utiliza de Prebisch na chave centro/periferia -, ou seja, uma estrutura produtiva historicamente determinada pelo desenvolvimento do capitalismo europeu, possuindo assim, características inteiramente distintas dos sistemas econômicos que lhe deram origem. Já o desenvolvimento, é compreendido por Furtado como um processo de homogeneização dessas estruturas híbridas (heterogêneas) mediante a realização da industrialização - tal homogeneização está diretamente atrelada ao processo de industrialização. Desta maneira o autor compreendia a indústria como um pólo dinamizador, considerando a industrialização periférica como um processo de desenvolvimento sem precedentes históricos e com graves problemas de cunho estrutural, gerados por um contexto de ineficiência gerencial.

Furtado, em sua análise do caso brasileiro, num entendimento de um quadro de subdesenvolvimento, como categoria e processo histórico que se atrelam às noções de cunho "cepalino" tais como a deterioração nas relações de troca; a estrutura agrária arcaica; as relações entre a monocultura exportadora e o imperialismo internacional; bem como a dualidade da estrutura produtiva e das relações de trabalho, compreende que essas resultavam numa economia com insuficiência estrutural, sem dinâmica econômica e sustentabilidade, numa sociedade dual com dificuldade de legitimação política, convertendo-se em profundas diferenças de interesses e enorme passivo social, que, consequentemente, gera grandes dificuldades na resolução dos conflitos sociais. Desse modo, o autor entende que se tem uma forte limitação à construção de uma sociedade moderna, com justiça social e democracia. Entretanto, mesmo com uma análise realista do perverso caso brasileiro, há nele um grande otimismo, sendo que, 
essas especificidades, significavam que havia um outro caminho a ser percorrido, uma jornada de desenvolvimento que diferia daquela seguida pelos países centrais.

Desse modo, tal como Raul Prebisch, Furtado entendia que nossas peculiares características que nos colocavam como um país subdesenvolvido teriam que ser superadas a par das formulações, explicações e mecanismos tradicionais das economias centrais. E é sob esta perspectiva que se desenvolve a construção de um projeto nacional de desenvolvimento em Celso Furtado, ao qual se busca para a nação um crescimento econômico permanente, com redistribuição de renda e redução das desigualdades regionais e sociais. $^{8}$ Para ele, a ausência de um projeto nacional inviabilizaria o desenvolvimento.

\section{A convergência prática-teórica}

Na construção desse projeto de desenvolvimento nacional, mesmo se utilizando da gramática da ciência econômica, Furtado transita disciplinarmente por várias áreas do conhecimento, tratando de teoria econômica - sobre a qual tem um domínio elevadíssimo -, investindo em história, política e sociologia, numa bela amarração em busca de um caminho de desenvolvimento econômico, social e cultural. Assim, desaguando num projeto de nação independente e autônomo, que pretende aferir eqüidade econômica e social, através da formulação e implementação de um programa de desenvolvimento econômico que perpassa o entendimento entre as classes sociais.

Nesse caso, um aspecto importante intrínseco a seu pensamento, bem como à sua trajetória pessoal, é que nota-se em Furtado uma convergência teórica e prática ${ }^{9}$, a qual ele se identifica e denomina "racionalidade superior". Assim, ele crê que os homens de inteligência ${ }^{10}$ podem e devem, necessariamente, corroborar no estudo e

\footnotetext{
${ }^{8}$ É relevante ressaltar que já em Formação econômica do Brasil de 1959, Furtado trabalha com o tema da construção, ou seja, a temática é intrínseca ao autor já no seu florescer intelectual, tecendo a construção econômica brasileira através dos ciclos da cana, da mineração, do café e da industrialização, numa análise da gradual superação da "heteronomia de destinos" concernentes à condição histórica no que tange a "internalização de decisões" e a conquista da soberania - que, segundo Juarez Guimarães (2000, p. 18), "[...] se impunham como horizonte e promessa".

${ }^{9}$ Gilbert (1984, p. 570) afirma que “[...] como espinha dorsal de toda sua obra, nota-se, por exemplo, a sua ânsia de ir além do esforço puramente analítico para produzir propostas de ação com finalidade de estimular o desenvolvimento."

10 Para Furtado, cabe ao intelectual o esforço para entender as transformações sociais de sua época, bem como elas se processam no contexto nacional e internacional, dessa forma, cabendo-lhe um esforço de ação transformadora através de uma atividade intelectual que desvende as relações sociais e aponte caminhos para uma ação prática, ou melhor, tomando de emprego um termo gramsciano, para a ação praxiológica - “[...] entender o mundo é uma maneira de agir sobre ele.” (FURTADO, 1997, p. 102)
} 
construção da nação - “[...] cabendo-lhes interpretar os valores em todos os campos da cultura, estão os intelectuais muito bem situados para identificar aquelas aspirações que traduzem as tendências mais profundas do sentir social." (FURTADO, 1964, p. 52) Isto é, esses devem colaborar para que se processe o desenvolvimento econômico e social, e como já referido, entendendo desenvolvimento como "[...] um processo de transformação que engloba o conjunto de uma sociedade" (FURTADO, 2000a, p. 41), que é estruturado ao longo de um processo de comportamento racional, da ação programada e de ação técnica. Para Furtado o desenvolvimento econômico é um meio essencial para o desenvolvimento humano e a realização de suas potencialidades integrais - "[...] a idéia do desenvolvimento está no centro da divisão do mundo que prevalece em nossa época. Nela se funda o processo de invenção cultural que permite ver o homem como um agente transformador do mundo. Dá-se como evidente que este interage com o meio no empenho de efetivar suas potencialidades." (FURTADO, 2000a, p. 7) O projeto de desenvolvimento nacional está intrinsecamente ligado à convergência teórica-prática imanente em Celso Furtado - “[...] um agente transformador do mundo", ou, como afirma Francisco de Oliveira (1983, p. 25) "[...] a obra furtadiana é uma obra para ação."

\section{A primazia do projeto nacional furtadiano}

Como bem analisa Juarez Guimarães (2000), a importância de Furtado acerca da temática de um projeto nacional

[...] está no fato de ele ser a primeira grande síntese de uma proposta de refundação republicana do Brasil. Isto é, em Celso Furtado amadurece pela primeira vez, em um campo teórico coerente, a solução de nossa problemática nacional mediante um projeto que prevê a superação de nosso quadro histórico de exclusão social em um quadro de aprofundamento dos fundamentos de nossa democracia política. (GUIMARÃES, 2000, p. 23)

Como herdeiro da tradição da ciência social brasileira nas quatro primeiras décadas do século XX, ele também partilha e concebe um pensamento para a ação transformadora. No entanto, vale ressaltar que Celso Furtado rompe com uma tradição do pensamento político brasileiro que até então concebia a ordenação estatal pautada 
sob um viés autoritário, no qual os preceitos de liberdade e democracia eram dados em segundo plano. ${ }^{11}$

[...] uma das contribuições mais significativas de Celso Furtado foi ter retirado "o Estado da boca da direita". A lógica de seu raciocínio coloca - ao contrário de autores como Oliveira Vianna e Alberto Torres, do caldo ideológico getulista e dos argumentos do autoritarismo militar - a esfera pública atrelada ao projeto de democratização e do aumento do bem-estar da população. Não custa lembrar que a presença do Estado, na maioria dos textos produzidos no Brasil desde o início do século, tinha uma clara conotação antidemocrática e conservadora, perpetuando o chamado pacto das elites. Os textos furtadianos refletem uma valorização extremada da democracia e da preservação das regras do jogo democrático. (CEPÊDA, 2001, p. 179)

Assim, mais uma vez ele é primaz, já que "[...] em Celso Furtado, as três dimensões da República - o destino nacional, a cidadania social e a soberania popular estão articuladas em uma lógica mutuamente configuradora." (GUIMARÃES, 2000, p. 24)

\section{Industrialização, Estado e desenvolvimento}

O desenvolvimento industrial como caminho para o desenvolvimento econômico e social ocupa lugar de destaque na obra de Furtado, constituindo um dos pilares do projeto nacional. Vera Alves Cepêda (2001), afirma que para ele o capitalismo era a única fórmula do progresso, sendo que a aceitação do capitalismo avançado significava indústria - "[...] o desenvolvimento econômico, hoje, é, basicamente, um processo de industrialização." (FURTADO, 1962, p. 68) Dentro dessa perspectiva do desenvolvimentismo $^{12}$, ao qual se enquadra Furtado, desenvolvimento está intrinsecamente ligado a industrialização, ou seja, desenvolvimento tem por carro chefe a industrialização, pois a ela tem para Furtado - bem como para os desenvolvimentistas - um sentido transformador.

A industrialização deveria contribuir para diversificar as exportações e ao mesmo tempo operar como alavanca da expansão do mercado interno. Condição necessária para que se reduzisse a desigualdade social era que a

\footnotetext{
${ }^{11}$ Podemos citar autores como Alberto Torres, Oliveira Vianna, Francisco Campos e Azevedo Amaral, que partilhavam deste pensamento e fizeram parte da construção do regime autoritário do governo de Getúlio Vargas.

${ }^{12}$ O conceito de desenvolvimentismo, segundo Bielschowsky (2000, p. 431), é "[...] definido como a ideologia de superação do subdesenvolvimento através de uma industrialização capitalista, planejada e apoiada pelo Estado."
} 
industrialização criasse empregos novos, assegurasse uma crescente oferta interna de bens-salários, a preços relativos declinantes e abrisse novas avenidas à exportação. Um país [...] como é o Brasil, não pode [...] privar-se de ter um sistema industrial relativamente integrado. Portanto, a inserção internacional tem que ser seletiva, o que requer planejamento. (FURTADO, 1990, p. 184-185)

Celso Furtado preconizou e defendeu a constituição de um capitalismo industrial moderno no país. Sob influência do keynesianismo, revelava uma decidida inclinação por ampliar a intervenção do Estado $^{13}$ na economia através de políticas de apoio à industrialização integrada, na medida do possível, num sistema de planejamento abrangente e incluindo investimentos em setores básicos. De modo que, uma industrialização sem planejamento pode oferecer riscos graves à economia e à sociedade, criando quadros estruturais de defasagens profundas. Furtado diagnostica que numa economia subdesenvolvida, na qual o mercado é entregue ao laissez-faire ${ }^{14}$, o capital acaba por agir de maneira corrosiva, pois investe em setores de rápido retorno de lucro, aumentando o estrangulamento e os gargalos estruturais que impedem a economia de alcançar a etapa de produção de bens de produção. Da mesma forma, produz um efeito de demonstração que agrava distorções do mercado consumidor; se utiliza da técnica da mais-valia absoluta para alcançar lucro "imediato", o que reduz o tamanho do mercado e debilita a capacidade de reprodução ampliada do capital; e ainda, consome a poupança (de investimento) em consumo suntuário. Furtado (1983, p. 40) afirma que "[...] o mito do laissez-faire [...] nas economias subdesenvolvidas tem servido para sancionar e consolidar a dependência."

Como pressupostos da construção e consolidação da Nação, Leda Maria Paulani destaca a posição de Furtado de que é

\footnotetext{
13 A idéia de um Estado interventor se realiza de modo a garantir o desenvolvimento, e, consequentemente, o bem-estar social e a estabilidade ao nível de ocupação plena da capacidade produtiva; atuando com eficiência na aplicação dos recursos de capital e aferindo o valor social dos investimentos - o que reforça o caráter social-democrata do Estado furtadiano. Entretanto, fica claro no pensamento de Furtado, acerca da intervenção estatal, que quando possível o Estado deve atuar com caráter mais indireto, com medidas de ordem monetária, fiscal, cambial e até mesmo de relativo controle dos preços e dos salários.

${ }^{14}$ A expressão laissez-faire representa um princípio defendido pelos economistas mais liberais e que defende que o Estado deve interferir o menos possível na atividade econômica e deixar que os mecanismos de mercado funcionem livremente. Na opinião dos economistas clássicos, entre os quais Adam Smith, o papel do Estado na economia devia limitar-se à manutenção da lei e da ordem, à defesa nacional e à oferta de determinados bens públicos que o setor privado não estaria interessado - tais como a saúde pública, o saneamento básico, a educação, as infra-estruturas de transporte, dentre outros.
} 
[...] preciso deixar de lado as idéias convencionais sobre vantagens comparativas, adotar o planejamento como instrumento primordial do Estado na superação do subdesenvolvimento e reforçar as instituições da sociedade civil. [...] para que essa construção se efetivasse, contudo, seria preciso, durante algum tempo, preservar o país das forças cegas do mercado, completar o processo de industrialização, planejar a redução das desigualdades regionais e da renda, além de fortalecer a sociedade civil no sentido da preservação das instituições democráticas, tudo concorrendo para o crescimento e o efetivo fortalecimento do mercado interno, única forma de garantir que ele não fosse destronado do posto de baliza do desenvolvimento do país. (PAULANI, 2001, p. 145-147)

Dessa maneira, no projeto de desenvolvimento, o capital privado deve ser fiscalizado e regulado pelo Estado. Furtado acredita que o Estado, por sua capacidade coordenadora - não sendo um agente econômico -, é capaz de pensar todos os segmentos e projetar alternativas e metas de longo prazo. ${ }^{15}$ Entende que a acumulação de capital nos setores estratégicos não podia aguardar a iniciativa e o arbítrio do capital estrangeiro, tendo a necessidade de controle e comando dos setores primordiais da economia, como transporte, energia elétrica, petróleo e mineração, bem como setores industriais básicos da grande indústria química e da siderurgia. ${ }^{16}$ Entretanto, para ele, nos demais setores industriais (setores não estratégicos) o capital estrangeiro era bemvindo como fomentador da economia - neste ponto é que aparece o posicionamento da necessidade de controle na questão das remessas de lucros, essa que era considerada uma séria ameaça ao equilíbrio do balanço de pagamentos e, consequentemente, à construção da industrialização. Destarte, mesmo os investimentos privados, deveriam obedecer à ordenação e regulação de um planejamento econômico, fazendo uma sistemática defesa da subordinação da política monetária e cambial à política de desenvolvimento econômico - argumentação que se opõe aos programas de estabilização preconizados pelo FMI -, desconsiderando as medidas de curto prazo para

\footnotetext{
${ }^{15}$ Isso, segundo Furtado, está na essência social do Estado interventor, que na busca do progresso nacional, não se submeteria ao mesmo princípio racional capitalista - "[...] como a mais poderosa organização dentro de uma sociedade, é perfeitamente natural que o Estado venha a desempenhar em muitas oportunidades um papel autônomo nos conflitos que caracterizam o desenvolvimento dessa sociedade." (FURTADO, 1964, p. 40) Enfatiza o autor que, "[...] o capitalismo interno, em face do livrecambismo dos exportadores e do setor agrícola em geral, necessita de forte proteção estatal para sobreviver. O setor agrícola, pressionado pelo núcleo capitalista, necessita de apoio creditício em larga escala para seguir adiante, o que somente o Estado está em condições de proporcionar. O setor exportador necessita de infra-estrutura de serviços básicos para instalar-se, e isso exige decisiva participação estatal." (FURTADO, 1964, p. 84)

${ }^{16}$ Segundo o autor " [...] o processo econômico, na fase mais avançada do capitalismo, exige a atuação progressiva de agentes de decisão centralizadores, como requisito imprescindível à manutenção da estabilidade em condições de desenvolvimento. Desta forma, as antigas economias laissez-faire tenderam a ser substituídas por outras mistas, em que o Estado controla diretamente importantes setores da produção, orienta a tecnologia e condiciona indiretamente os investimentos do setor privado." (FURTADO, 1964, p. 75)
} 
o controle inflacionário. A importância dada ao caráter interventor que o Estado deveria assumir, resulta da concepção de que somente através da coordenação estatal seria possível internalizar os centros de decisão sobre os destinos da economia brasileira, rompendo com as relações de submissão frente às economias centrais, em prol da emancipação econômica nacional. Furtado postula um projeto nítido de Nação autônoma - econômica e politica - por meio de uma reversão do quadro desigual das relações entre centro e periferia capitalista. A ação do Estado interventor furtadiano vem criar condições para que a economia cresça e se consolide, a partir de uma ação planejada.

Para ele, as mudanças no sistema econômico nacional advindas do crescimento e desenvolvimento industrial, para sua progressiva expansão de maneira sustentável, necessitam de planejamento, incentivo e proteção do Estado ao setor industrial, bem como a criação de políticas econômicas que estimulem mudanças de hábitos de consumo, superação da ocupação arcaica fundiária, mudanças na distribuição da riqueza como meio de aquecer e expandir o mercado interno. A distribuição de renda é defendida como princípio fundamental do equilíbrio dinâmico do capitalismo, colocando ênfase não na acumulação, mas na distribuição de riquezas ${ }^{17}$, na diminuição das desigualdades regionais, dentre outros. Para Furtado, o Estado deveria corporificar as demandas sociais de uma economia então emergente, equacionando suas contradições e garantindo sua autonomia e sua sustentabilidade.

[...] o trabalho de reconstrução estrutural requerido para superar o subdesenvolvimento baseia-se numa racionalidade mais abrangente do que a dos mercados, e a ela só se tem acesso pelo planejamento. Dentro do quadro estrutural criado pela economia primário-exportadora, o crescimento econômico tende a reproduzir, agravadas, as desigualdades sociais características do subdesenvolvimento. Não se trata de ampliar o papel empresarial do Estado, o que veio a ser feito no Brasil por outras razões, entre estas a falta de planejamento. Trata-se de prevenir as resistências estruturais à redução das desigualdades sociais, de orientar o esforço de acumulação prioritariamente para a satisfação das necessidades básicas da população. (FURTADO, 1990, p. 185)

\footnotetext{
${ }^{17}$ Segundo o autor, “[...] desenvolvimento, por definição, significa aumento da disponibilidade de bens e serviços para fins de consumo e investimento. E não há aumento de investimento, numa economia de livre empresa, sem haver também aumento do consumo. Desta forma, desenvolvimento é aumento do consumo, e aumento do consumo não pode ser identificado como forma alguma de sacrifício. Ocorre, entretanto, que desenvolvimento também significa criação de expectativa de melhoria para o conjunto da população: aumenta o emprego urbano rapidamente, intensifica-se a mobilidade social, cresce o efeito de demonstração, a simples manutenção do status social passa a exigir melhora permanente das condições materiais de vida." (FURTADO, 1962, p. 41)
} 
Para Maria Regina Nabuco,

\begin{abstract}
As idéias de projeto nacional e de Estado encontram-se profundamente ligadas na obra de Furtado. Sem o Estado e sua racionalidade superior, o projeto nacional não se implementaria. Ao mesmo tempo, este Estado deveria corporificar as demandas sociais de uma economia emergente, equacionando suas contradições e garantindo sua autonomia e sua sustentabilidade. (NABUCO, 2000, p. 61)
\end{abstract}

Celso Furtado, no que diz respeito ao papel do Estado, defende que este deve apoiar e desenvolver políticas de manutenção e ampliação da renda do setor dinâmico capitalista - através de políticas fiscais, cambiais e de apoio aos investimentos -, e, por conseguinte, as inter-relações produtivas desse setor com os demais setores. ${ }^{18}$ Deve, nesse sentido, promover o desenvolvimento econômico, apoiando os segmentos mais avançados do capitalismo nacional, contrariando forças externas e as classes proprietárias não identificadas com um desenvolvimento com objetivo de longo prazo e mais amplo - de viés econômico e social. Furtado imprime ao Estado uma racionalidade superior que é por si só legitimadora. Dessa maneira, o Estado atua como construtor, condutor e como árbitro dos processos econômico-sociais ${ }^{19}$ - "agente propulsor e orientador das atividades econômicas e árbitro dos conflitos de classe na definição do interesse nacional." (FURTADO, 2000, p. 41)

Observa-se então, no pensamento de Furtado acerca da Nação, a convergência e a identificação entre força política e força econômica, de modo que para ele um Estado fraco seria sinônimo de economia fraca e, inversamente, uma economia fraca impediria a constituição de um Estado forte. Assim, ambas resultariam numa falta de autonomia ${ }^{20}$ nacional e num empecilho ao desenvolvimento. Daí a importância dada pelo autor à relação político-econômica, como salienta Vera Cepêda (2006, p. 63) equalizando a teoria econômica (como meio) para a definição de um projeto político (como fim) e no

\footnotetext{
${ }^{18}$ Numa concepção cíclica virtuosa desse movimento, o apoio ao investimento no setor dinâmico leva à obtenção de "objetivos macroeconômicos", ou seja, de auxilio a novos investimentos, gerando assim mais emprego, mais renda, mais consumo, etc.

19 Tal legitimação liga-se à relação político-econômica, no princípio da luta de classes dentro de um quadro político dual, no qual há um enfraquecimento de setores não dirigentes, o que dá margem para que o Estado tenha e exerça maior poder. Desse modo o Estado obtém relativa independência, se transformando então em árbitro (capaz) dessa sociedade de brutal conflito social.

20 José Luís Fiori (2000) afirma que a condição essencial do seu projeto político-econômico, na sua concepção de uma "formação econômica nacional" está atrelada a autonomia decisória. Nesse sentido, Furtado coloca que era necessária a criação "[...] dentro do território brasileiro, de um sistema econômico articulado e capacitado para autodirigir-se [por meio] de centros de decisão consistentes e autônomos." (FURTADO, 1975, p. 79)
} 
qual a figura chave para pensar o desenvolvimento democrático é a Nação. Ainda conforme Cepêda,

[...] a aposta furtadiana, que em sua tese central fortalece de maneira radical o poder e o papel do Estado (e de seus grupos funcionais internos), é que este precisa ser controlado pela sociedade, principalmente em sua função de promotor do desenvolvimento. Ou seja, há em seu raciocínio em determinação recíproca entre economia e política em dois níveis: o projeto de futuro passa pela economia, mas tem um telos social (é desenvolvimento e não mero crescimento econômico), sendo que para realizar a economia as ferramentas adotadas vêm do campo político e não estritamente econômico: conflito distributivista, regulação pela arena competitiva da democracia e da 'opinião pública', regulação e projeto de estruturação econômica orquestrados e mediados pelo Estado. (CEPÊDA, 2006, p. 62-63)

\section{Diagnóstico, reformas e democracia}

Dessa maneira, Furtado diagnostica que existem entraves à ação fomentadora do Estado no tocante às políticas estatais de implementação e promoção do desenvolvimento. Esses entraves têm sua causa central em dois pontos: a falta de eficácia do Estado e a não representatividade de uma grande parcela da população, ambas devidas ao dualismo brasileiro - " [...] a notória tendência para a estagnação que caracteriza muitas das atuais economias subdesenvolvidas tem raízes profundas nas estruturas sociais." (FURTADO, 1964, p. 84). Acerca do primeiro ponto, o autor analisa que a eficácia do Estado é afetada pelo dualismo de valores, que resulta da dicotomia estrutural da economia, no qual o arcaico convive com o moderno, mas sem o primeiro ser adequadamente absorvido pelo segundo, o que reforça e impõe o choque de interesses entre as classes conservadoras $\mathrm{e}$ as progressistas. $\mathrm{O}$ segundo ponto, amplamente exposto em A Pré-Revolução Brasileira (1962), Subdesenvolvimento e Estado democrático (1962) e Brasil: a construção interrompida (1992) refere-se à falta de representatividade de grande parte da população, analisando que a classe dos trabalhadores do setor industrial não desenvolveu suficientemente sua "consciência de classe", e como agrave desse quadro, que os camponeses vivem apenas em condição de massa. Desse modo, não há integração e sim um bestial dualismo que tende ao automatismo do mercado e a reprodução dessa estrutura social. Portanto, Furtado entende que esse automatismo reprodutivo, que deteriora a sociedade brasileira e rechaça sobremaneira o desenvolvimento, só pode ser quebrado e/ou reduzido por uma crescente homogeneização social via evolução material, e por uma equivalência - leia- 
se equidade - de direitos sociais das classes dominadas e das camadas diligentes no trato político, para que os mais carentes não sejam privados dos benefícios do desenvolvimento. ${ }^{21}$ Isto porque uma grande parcela da sociedade não pode reivindicar a proteção das leis e do Estado, sendo excluída de qualquer política baseada na reciprocidade ou no consenso, além de, por fatores sociais estruturais de dominação educação, segurança, moradia, dentre outros -, tenderem a ser manipulados pela classe dirigente.

Assim como Robert Dahl (1997) ${ }^{22}$ e Adam Przeworsky ${ }^{23}$ (1989), Furtado percebe o papel do Estado e da maior participação política dos setores populares como uma forma superior e inevitável de organização das relações socioeconômicas na sociedade moderna, afirmando em O longo amanhecer (1999) que o ponto de partida de qualquer novo projeto alternativo de Nação terá que ser, inevitavelmente, o aumento da participação e do poder do povo nos centros de decisão do país. Portanto, o autor defende que é com o aumento da participação e da representação política das massas via sindicatos, opinião pública, voto, dentre outros - na luta contra os interesses patrimonialistas oligárquicos, que se construirá a modernidade brasileira.

Segundo José Luís Fiori (2000), a formação de um sistema econômico nacional brasileiro em Furtado teria três condições indispensáveis:

[...] a primeira seria a criação e o fortalecimento de centros endógenos de decisão capazes de dar-nos 'a faculdade de ordenar o processo acumulativo em função de prioridades estabelecidas por nós mesmos'; a segunda seria que este processo fosse acompanhado por uma crescente homogeneização da sociedade, capaz de abrir espaço para a realização do potencial da cultura brasileira; e a terceira, finalmente, que a própria idéia da formação se fizesse vontade coletiva e projeto político capaz de acumular a força indispensável para transformar a agenda das prioridades nacionais em dimensão política do cálculo econômico. (FIORI, 2000, p. 34)

\footnotetext{
${ }^{21} \mathrm{O}$ trato da questão política tem um peso determinante no desenvolvimento econômico proposto por Furtado, possibilitando reduzir e eliminar a influência política dos setores mais atrasados da sociedade e, ao mesmo tempo, checar a eficiência dos projetos de modernização do país, ficando nítido que, para ele, a participação exige ganhos para as classes trabalhadoras que só poderiam ser satisfeitos com o desenvolvimento econômico.

${ }^{22}$ Dahl (1997) propõe uma "teoria pluralista de democracia", afirmando que o modelo democrático de governo deve buscar assegurar a máxima representação política, afastando-se da concepção elitista (schumpeteriana). De modo que, na relação entre representação e pluralidade entraria o papel do Estado como árbitro na distribuição de poder, garantindo que não haja excessiva concentração em um setor ou classe. Outro ponto convergente nas obras de Dahl e Furtado é a evolução da democratização das poliarquias (definidas como a representação realizável do ideal democrático), através do aumento da possibilidade de contestação pública (liberalização) e participação (inclusividade).

${ }^{23}$ Para Przeworsky (1989) a participação política dos trabalhadores é a via de efetivação dos interesses dos trabalhadores, de modo que a participação no jogo democrático habilita os trabalhadores a terem acesso às negociações sobre o trabalho.
} 
A construção do sistema econômico nacional brasileiro nos moldes explicitados acima pressupõe que modificações estruturais deveriam ser realizadas. Daí a importância das reformas de base que, para Furtado, têm a finalidade de reduzir os desajustes estruturais que se efetivam no plano político e econômico. Esses descompassos estruturais são advindos do quadro histórico brasileiro e da acelerada industrialização, bem como, em conseqüência, da também rápida transformação do setor industrial no principal centro dinâmico da economia, o que, por conseguinte, repercute em tensões em todos os âmbitos da sociedade brasileira. Assim, as reformas estão intrinsecamente ligadas à arbitragem e ao ajuste na construção do desenvolvimento tendo, dessa maneira, a função de ampliar o aparelho do Estado, desenvolvendo a burocracia e aumentando a eficácia das ações políticas e sociais públicas de desenvolvimento. Mais precisamente, “[...] essas novas políticas exigem uma redefinição das funções do Estado e uma total reestruturação administrativa deste [...] condição indispensável ao êxito da política de desenvolvimento e reconstrução do país." (FURTADO, 1962, p. 79).

Nesse sentido, a tarefa básica para Furtado estava em promover

[...] maior elasticidade às estruturas. Temos que caminhar com audácia para modificações constitucionais que permitam realizar a reforma agrária e modificar pela base a maquinaria administrativa estatal, o sistema fiscal e a estrutura bancária. Temos que subordinar a ação estatal a uma clara definição de objetivos de desenvolvimento econômico e social, cabendo ao Parlamento estabelecer diretrizes, mas retirando-se aos políticos locais o poder de discriminar verbas. Temos que dar meios ao Governo para unir efetivamente aqueles que malversem fundos públicos, para controlar o consumo supérfluo, e para dignificar a função de servidor do Estado. Devemos ter um estatuto legal que disciplina a ação do capital estrangeiro, subordinando-o aos objetivos do desenvolvimento econômico e da independência política. Deve o Governo dispor de meios para conhecer a origem de todos os recursos aplicados nos órgãos que orientam a opinião pública. E acima de tudo devemos ter um plano de desenvolvimento econômico e social à altura de nossas possibilidades e em consonância com os anseios de nosso povo. (FURTADO, 1962, p. 32)

Em A Pré-Revolução Brasileira, Furtado discute o anacronismo de nosso aparelho de administração pública, criticando a resistência oferecida às mudanças requeridas a estrutura administrativa. Ele é incisivo ao afirmar que

[...] o Estado não está devidamente aparelhado para exercer nenhuma das funções básicas de uma política de desenvolvimento econômico. As políticas monetária, fiscal, de exportação e importação, cambial, de fomento industrial, de assistência técnica à agricultura, dependem todas, entre nós, de medidas mais ou menos improvisadas e quase sempre tomadas de forma desconexa. $\mathrm{O}$ aparelho administrativo não permite o mínimo de integração para que essas 
distintas políticas visem objetivos de conjunto. [...] nenhuma tarefa é mais urgente, neste país, do que aparelhar o Estado para a luta pelo desenvolvimento. (FURTADO, 1962, p. 78)

Para ele a forma como se efetivam essas modificações depende, em boa medida, do grau de flexibilidade do marco institucional dentro do qual opera a economia, apontando o modelo democrático como o mais viável, e, desse modo, o caminho a ser trilhado pelo Brasil. Dessa relação, democracia-reformas (numa dinâmica reformista de cunho estrutural que se processa dentro da ordem - democrática), resulta a grande importância das reformas no caso brasileiro. Elas se constituem em condição essencial para que se processe o desenvolvimento de modo pleno e virtuoso, rompendo assim com os entraves e as amarras histórico-estruturais, fortalecendo o sistema político democrático $^{24}$.

O projeto nacional furtadiano reitera a necessidade de uma mudança social, que tem na sua centralidade política um projeto de capitalismo democrático ${ }^{25}$, defendendo a institucionalidade democrática republicana como pilar do processo de desenvolvimento econômico, que só teria êxito com representatividade social e distribuição de renda. Como afirma Leda Maria Paulani (2001, p. 153), para Furtado “[...] sem a reversão da concentração de renda e o fortalecimento da sociedade civil, a industrialização não seria suficiente para consolidar a economia nacional e para sustentar o mercado interno como seu pólo dinâmico.” Já, para Vera Cepêda (2001), a mudança social ${ }^{26}$ é, portanto, fundamental para o desenvolvimento global - econômico, social, cultural, institucional, dentre outros. E, assim como a mudança se processa criando conflitos inevitáveis, a coesão social e a perspectiva de progresso dependerão de um mecanismo democrático que mantenha o conflito dentro dos limites institucionais, extraindo dele a força

\footnotetext{
${ }^{24}$ Vale ressaltar que boa parte das reformas propostas e categoricamente defendidas por Furtado, ainda não se efetivaram, de modo que os entraves continuam postos e a democracia ainda fragilizada nos seus mecanismos políticos de efetivação referentes à cidadania, representação e participação.

${ }^{25}$ A defesa da democracia por Furtado, está na crença que o desenvolvimento da sociedade democrática resultaria numa progressiva eliminação dos "privilégios" que operam anti-socialmente, e freiam a expansão das forças produtivas e entorpecem o desenvolvimento social. Entendendo que crescimento leia-se desenvolvimento -, democracia e liberdade estão diretamente atreladas, analisando que "[...] a causa do progresso das liberdades nas sociedades democráticas capitalistas [é] a crescente estabilidade institucional destas." (FUTADO, 1964, p. 48)

${ }^{26}$ Na primeira parte de Dialética do Desenvolvimento (1964) desenvolve-se uma teoria da mudança social no qual, se valendo de argumentos do materialismo histórico, através da análise da história como sistema (relações de determinação) dotado da capacidade de movimento e transformação, Furtado afirma que em seu processo, as relações econômicas é que dão o impulso inicial de transformação, produzindo por extensão, ou seja, pelas relações de determinação entre o todo e as partes, novas relações institucionais numa bipartição infra-estrutura/superestrutura -, e assim, um novo quadro de desenvolvimento.
} 
necessária para a evolução econômica e o confronto com as estruturas anacrônicas. Com efeito, “[...] a democracia aparecia, em Furtado, como o meio mais apropriado para canalizar as tensões geradas pelo processo de desenvolvimento da economia e da sociedade brasileira; como forma, portanto, de superar o subdesenvolvimento e de realizar o velho sonho de constituir de fato a Nação Brasileira." (CEPÊDA, 2001, p. 181) Furtado posiciona os antagonismos do conflito no centro do projeto nacional, pois compreende que a articulação e a pressão dos trabalhadores por melhores salários e melhores condições de vida, são fundamentais para o aumento do tamanho e consumo do mercado interno, bem como obrigaria os capitalistas a uma constante renovação tecnológica - ao adotarem o ciclo da inovação schumpeteriana -; e no campo da sociedade civil e do Estado, reforçaria o marco institucional democrático, modelando, orientando e fiscalizando a ação planejadora do Estado e a distribuição de seus recursos.

Quanto mais ampla a base de um governo representativo, mais este estará em condições de captar as tensões sociais criadas pelos obstáculos ao desenvolvimento e traduzi-las em linguagem política. Por esta forma, abre-se caminho para o debate e a identificação de denominadores comuns que permitirão somar forças capazes de impor uma solução com o mínimo de dano para o marco institucional. (FURTADO, 1964, p. 73)

\section{Social-democracia e a refundação republicana}

Assim, o projeto nacional proposto por Celso Furtado tem aspiração socialdemocrata, que por definição, aparece como uma forma "ideal" de democracia representativa, constituindo-se numa corrente política que pretende corrigir as injustiças sociais e melhorar as condições de vida da população através de reformas livremente consentidas pela sociedade dentro de um regime democrático, no qual deve haver igualdade e justiça social, não somente perante a lei, mas em termos econômicos e socioculturais.

SOCIAL-DEMOCRACIA. Corrente política de tendência socialista, que [...] propõe a mudança da sociedade capitalista por meio de reformas graduais, obtidas dentro das normas constitucionais da democracia representativa. Nesse sentido, os social-democratas defendem uma política governamental voltada para a estatização de setores básicos da economia, [...] tributação sobre os lucros das grandes empresas, co-gestão operária nas indústrias, assistência médica e educação gratuita para toda a população, segurodesemprego, amplas liberdades sindicais e livres negociações coletivas entre patrões e empregados [...]. (SANDRONI, 1999, p. 566) 
A social-democracia visa a manutenção e ampliação das liberdades democráticas, pela valorização do trabalho e a elevação do nível de vida dos trabalhadores, bem como pela subordinação do poder econômico ao controle democrático da sociedade, conforme o modelo de Estado concebido e projetado pelo autor. Segundo ele, “[...] se deixamos de lado toda referência ao sistema econômico nacional e a produtividade social, a idéia mesma de política econômica perde seu significado corrente." (FURTADO, 2000b, p. 8)

A concepção de Estado de Celso Furtado se enquadra claramente numa proposta de Estado de bem-estar ${ }^{27}$, de acordo com suas próprias palavras: “[...] é objetivo precípuo da ação estatal promover padrões mais altos de bem-estar social [...]". (FURTADO, 1962, p. 73) Sobretudo, Furtado destaca que quanto maior for a heterogeneidade social, maior será a necessidade de uma política nacional de desenvolvimento que priorize o crescimento e o bem-estar social de toda a população. Sua concepção, de maneira geral, se baseia na existência de uma proximidade com relação às idéias de estabilidade da produção capitalista, por meio da acumulação de capital permanente; numa legitimidade do Estado baseada na idéia de que o desenvolvimento é um objetivo coletivo $^{28}$ e superior - do ponto de vista da racionalidade do planejamento -; e numa confiança da sociedade -notadamente dos empresários - na estabilidade das expectativas de risco, via expansão do mercado consumidor. Para Umberto Cerroni (1993, p. 154), “[...] o Estado Social propõe, de fato, uma intervenção sistemática com o objetivo de promover e garantir o bem-estar [...]”, sendo que "[...] uma característica saliente do Estado do Bem-Estar é a dimensão economicista que nele assume a atividade política". Furtado corrobora essas questões em outras passagens:

\footnotetext{
${ }^{27}$ Claro que os conteúdos de ordem histórico-culturais da obra de Celso Furtado, apontam para a especificidade do caso brasileiro - tido como subdesenvolvido -, sendo este de complexidade crescente na implantação e êxito do "modelo" do Estado de bem-estar, o que reforça o caráter providencial do planejamento visando sua eficácia. Maria Regina Nabuco afirma que para Furtado, "[...] são também estas especificidades que apontam para a impossibilidade de um crescimento econômico permanente, com redistribuição de renda e redução de desigualdades regionais e sociais, na ausência de um projeto político nacional." (NABUCO, 2000, p. 61)

28 "Um sistema econômico nacional não é outra coisa senão a prevalência de critérios políticos que permitem superar a rigidez da lógica econômica na busca do bem-estar coletivo." (FURTADO, 1992, p. 30) "[...] não apenas da acumulação depende o desenvolvimento. Apóia-se este, igualmente, na força dinâmica que surge nas sociedades sob a forma de impulso para a melhoria das condições de vida. (FURTADO, 1964, p. 64)
} 
A política de desenvolvimento que se requer em um país subdesenvolvido é, principalmente, de natureza qualitativa: exige um conhecimento da dinâmica das estruturas que escapa à análise econômica convencional. (FURTADO, 1962, p. 38)

[...] em um país subdesenvolvido típico como o nosso. Para alcançar os ideais de bem-estar social e melhoria das condições de vida do país, não nos basta preservar a estabilidade do sistema econômico. (FURTADO, 1962, p. 75)

Dessa maneira, reitera-se que o projeto nacional furtadiano, pelas suas bases e características, bem como sua essência, se define como social-democrata. Por conseguinte, há na obra de Celso Furtado, como analisa Juarez Guimarães (2000), uma "refundação republicana" 29 que no plano da cultura política, envolve quatro dimensões fundamentais: a) a refundação ético-política dos fundamentos em que se assenta o contrato social do Estado brasileiro: referentes aos princípios que definem os direitos e os deveres básicos dos cidadãos, passando pela crítica ao caráter patrimonialista reinante em nossa sociedade - de modo que este breca as modificações sociais e institucionais de suma importância ao desenvolvimento (reforma agrária ${ }^{30}$, reforma tributária, respeito aos direitos do trabalho, dentre outros) -, bem como a crítica da racionalidade formal dos mercados e o livre funcionamento dos mesmos (laissez-faire); b) a reconstrução do setor público estatal: para ser o agente que imprime e conduz o desenvolvimento, o Estado deveria sofrer alterações - "nem privatista nem estatista",31 -, já que, à medida que o desenvolvimento entra em curso, novas demandas requerem sua ampliação, o que necessitaria de uma maior eficiência e integração estatal; c) a democratização dos fundamentos de nossa democracia política: com a construção de bases sociais através da ampliação da cidadania, da superação das distorções no sistema de representação e da retomada de uma dinâmica federativa; d) uma revisão das bases históricas de heteronomia em que se deram as relações do Brasil com o centro capitalista: com destaque e valorização do autônomo e do nacional ${ }^{32}$ no que concerne o

\footnotetext{
${ }^{29}$ Guimarães observa que “[...] esta refundação republicana reivindica a formação de uma vontade nacional reformadora que solicita e, ao mesmo tempo, questiona as próprias tradições políticas brasileiras." (GUIMAR ÃES, 2000, p. 30)

30 Para Furtado a reforma agrária se constitui em elemento viabilizador da industrialização, já que ao mesmo tempo que cria mercado interno, aumenta a oferta de alimentos, desbloqueando a acumulação por impedir o aumento dos salários nominais.

${ }^{31}$ Uma reforma administrativa do Estado que desvincule sua burocracia dos interesses patrimonialistas e rentistas, na tentativa de criar uma gerencia moderna e mais pública do Estado brasileiro.

${ }^{32} \mathrm{O}$ nacionalismo para Furtado é o espaço nacional, o meio onde se constitui, no qual se constrói o processo democrático e afirma-se a sinergia social, no qual se coloca a possibilidade concreta de intervenção, do povo e das classes sociais dominadas, ao alcance de suas possibilidades civis e políticas.
} 
Estado, numa reconfiguração das relações internacionais, em que ganha ênfase a criação de uma sinergia positiva entre acumulação e expansão do mercado interno, bem como a integração da América latina.

Furtado propunha a superação do subdesenvolvimento através de um projeto nacional que passava pela industrialização, o fortalecimento do mercado interno, a redução da desigualdade social e a distribuição de renda, numa elevação do nível de bem-estar da população, condicionada pelo planejamento, transformações estruturais, política econômica adequada, afirmação cultural, e uma construção nacional-soberana do desenvolvimento. Isso projeta o pensamento de Celso Furtado para além do campo específico da economia e explicita que os rumos econômicos estão condicionados e intrinsecamente relacionados ao campo da política e suas escolhas, numa ampliação dos direitos civis, políticos e sociais, que formam o tripé da cidadania moderna.

\section{Considerações finais}

Lamentavelmente, a par do projeto nacional, o que Furtado presenciou a partir dos anos 1970 foi um Estado que não amortizou os conflitos sociais, e sim serviu aos interesses da burguesia internacional por meio de arrocho salarial, da modernização tecnológica dependente e da concentração de renda, desprezando a importância do consumo interno para um crescimento econômico sustentável. Numa contraposição brutal à idéia nacional-desenvolvimentista do setor público - ao qual pertencera Furtado -, concebeu-se o desenvolvimento de modo associado. Assim, num tripé Estado, capital nacional e capital internacional, adotou-se uma política na qual o "Estado não é o árbitro da eqüidade, mas o agente modernizador e repressor com relação a qualquer movimento redistributivo e de ampliação de direitos civis" (NABUCO, 2000, p. 69). O que resultou numa extrema situação de dependência externa agravada pelo governo FHC, numa mídia privatista de cunho neoliberal e num conservadorismo autodestrutivo enraizado em todas as classes sociais - originário do trágico desmantelamento da cultura política empreendido pelos anos de chumbo.

Por conseguinte, com o passar dos anos, a fantasia se desorganizou, mas não completamente. Despida a máscara da globalização liberal dependente, numa conjuntura de crise econômica em que processava-se "a crise do paradigma liberal", o pensamento furtadiano naturalmente reapareceu. Sobretudo a partir do segundo governo Lula compareceu em parte, através das políticas distributivas de renda - recuperação 
real do salário mínimo, Bolsa Família, crédito para os de baixa renda, dentre outros -, a tão defendida questão da distribuição de renda e do fortalecimento do mercado consumidor interno como política e ação do Estado. Porém, ainda na contramão da concepção de desenvolvimento e do projeto nacional de Celso Furtado, se opõem importantes fatores, dentre eles destaco: a manutenção de uma ação governamental que se fundamenta no livre jogo de mercado, que não adota o planejamento como ação governamental central, ou seja, como política de Estado e não como política de governo - sobretudo, o planejamento democrático -; a convivência com o patrimonialismo, o clientelismo e a corrupção; a aceitação e estímulo a livre movimentação internacional de capitais (especulativos ou não); a utilização das altas taxas de juros como instrumento central no combate à inflação, deixando a taxa de câmbio flutuar livre e amplamente, chegando a aceitar uma moeda ficticiamente valorizada frente ao dólar - sacrificando a competitividade da indústria brasileira no mercado interno e externo -; a manutenção de uma carga tributária exorbitante (em torno de 36\%, sendo uma das mais altas do planeta); o cultivo de um gradativo desgaste da qualidade do ensino educacional e não investimento em capacitação - aumentando os gargalos estruturais referentes a mão-deobra e os setores produtivos de maior valor agregado, indo na contramão da ideia furtadiana de concentrar os investimentos no aperfeiçoamento do fator humano para elevar o nível cultural da população e ampliar a oferta de quadros técnicos -; a priorização do investimento no setor de exportações ${ }^{33}$; a não promoção da inclusão, sobretudo, da inclusão cidadã que consta na Constituição de 1988, de modo que a inserção realizada tem preceitos neoliberais, de inclusão via mercado - que visa suprir a falta de mão-de-obra e criar consumidores, e não cidadãos, gerando os denominados cidadãos de segunda classe -; sobretudo, o descaso do governo para a realização das tão necessárias reformas de base (fiscal, política, tributária, agrária, etc.), e que, em detrimento do social e da infra-estrutura, corta gastos para pagar juros a credores

\footnotetext{
${ }^{33}$ Vide o artigo da economista Luciana Badin Pereira Lima (2007) sobre os investimentos previstos para o período 2007-2010 pelo BNDES. A autora analisa que o Brasil está adotando uma estratégia de desenvolvimento que se assenta sobre setores que produzem para exportação, sendo a maior parte desses investimentos de caráter autônomo em relação ao mercado interno e correspondendo a movimentos da expansão e deslocamento da economia mundial. Luciana Badin Pereira Lima questiona "[...] como o BNDES e os demais responsáveis pelo financiamento do modelo adotado avaliam a aposta em uma estratégia de desenvolvimento, que concentra de maneira tão gritante nossa atividade econômica em setores extrativistas e de insumos básicos, voltados para alimentar as indústrias dos países desenvolvidos, que não dependem em nada da melhoria da renda de nossa população, que tem um poder de irradiação para o conjunto da economia limitado, e que incentiva a ampliação desmedida de setores cuja viabilidade econômica depende do fornecimento de energia a baixo custo e/ou estão no centro de conflitos socioambientais?" (2007, p. 12-13)
} 
internacionais - vide os cortes consecutivos nos orçamentos anuais nas áreas da saúde, segurança, educação, defesa, etc. Percebe-se, infelizmente, que seu projeto nacional ainda não encontrou respaldo efetivo nas políticas públicas estatais no Brasil.

Por isso é tão importante o aprofundamento e a discussão do olhar furtadiano sobre o caso brasileiro, pois o diálogo e o projeto que ele propõe se mostra ainda atual e tem muito que acrescer ao desenvolvimento do Brasil - desenvolvimento expresso no rigor e amplitude da definição de Celso Furtado. Resta-nos e ainda nos conforta, a certeza de que por sua força e competência intelectual, bem como pela sua idoneidade ética, o vigor de seu pensamento seguirá como referencial estratégico enquanto houver subdesenvolvimento. Assim, a fantasia não será desfeita.

\begin{abstract}
This article discusses the thought of Celso Furtado having as its central theme the defense that there is in his work a national project for Brazil. Noting that this national project goes beyond in the right of the economic bias and also includes the political, social and cultural aspects, on the other words, it proposes "development" in the stringency of the furtadian definition. thus, this project flows into a building of a republican and democratic nation, economically strong and with social equity.
\end{abstract}

Key words: Celso Furtado; National Project; Development; Democracy; Nation.

\title{
Referências
}

BIELSCHOWSKY, Ricardo A. Pensamento econômico brasileiro: o ciclo ideológico do desenvolvimento. 4. ed. Rio de Janeiro: Contraponto, 2000. 480p.

CEPÊDA, Vera Alves. O pensamento político de Celso Furtado - desenvolvimento e democracia. In: BRESSER-PEREIRA, Luiz Carlos; REGO, José Marcio. (Org.). A grande esperança em Celso Furtado. São Paulo: Editora 34, 2001, p. 167-184.

CEPÊDA, Vera Alves. Estado, democracia e nação na teoria do subdesenvolvimento. Revista Versões, v. 1, p.49-68, 2006.

CERRONI, Umberto. Política: métodos, teorias, processos, sujeitos, instituições e categorias. São Paulo: Brasiliense, 1993. 222p. 
DAHL, Robert. Poliarquia: Participação e oposição. São Paulo: EdUSP, 1997.

FIORI, José Luís. A propósito de uma "construção interrompida". In: TAVARES, Maria da Conceição (Org.). Celso Furtado e o Brasil. São Paulo: Perseu Abramo, 2000, p.33-57.

FURTADO, Celso. A pré-revolução brasileira. Rio de Janeiro: Fundo de Cultura, 1962. 116p.

FURTADO, Celso. Subdesenvolvimento e Estado democrático. Recife: Comissão de Desenvolvimento Econômico de Pernambuco, 1962. 53p.

FURTADO, Celso. Dialética do desenvolvimento. 2. ed. Rio de Janeiro: Fundo de Cultura, 1964, 181p.

FURTADO, Celso. Desenvolvimento e subdesenvolvimento. 3. ed. Rio de Janeiro: Fundo de Cultura, 1965, 258p.

FURTADO, Celso. Um projeto para o Brasil. 5. ed. Rio de Janeiro: Saga, 1969, 133p.

FURTADO, Celso. A hegemonia dos Estados Unidos e o subdesenvolvimento da América Latina. Rio de Janeiro: Civilização Brasileira, 1975, p.192.

FURTADO, Celso. Cultura e desenvolvimento em época de crise. Rio de Janeiro, Paz e Terra, 1984, p. 30-41.

FURTADO, Celso. Entre inconformismo e reformismo. Estudos Avançados (IEA USP), v.4, nº. 8, p. 166-187, São Paulo, Jan./Abr. 1990.

FURTADO, C. A fantasia organizada. In: Obra autobiográfica. São Paulo: Paz e Terra, 1997. cap.1-14, p.87-359.

FURTADO, Celso. Brasil: a construção interrompida. 2. ed. São Paulo: Paz e Terra, 1992. 87p.

FURTADO, Celso. Formação econômica do Brasil. 29. ed. São Paulo: Nacional, 1999. 248p.

FURTADO, Celso. O longo amanhecer: reflexões sobre a formação do Brasil. 2.ed. São Paulo: Paz e Terra, 1999. 116p.

FURTADO, Celso. Introdução ao desenvolvimento: enfoque histórico-estrutural. 3. ed. Rio de Janeiro: Paz e Terra, 2000a. 126p.

FURTADO, Celso. O fator político na formação nacional. Estudos Avançados (IEA USP), v.14, no. 40, p.7-12, 2000b.

FURTADO, Celso; OLIVEIRA, Francisco de. Celso Furtado: economia. São Paulo: Ática, 1983. 224p. 
FURTADO, Celso; CAMARGO, Aspásia; LOYOLA, Maria Andréa. Celso Furtado entrevistado por Aspásia Camargo e Maria Andréa Loyola. Rio de Janeiro: UERJ, 2002. 49p.

GALBRAITH, John Kenneth. O novo estado industrial. 3.ed. São Paulo: Nova Cultural, 1988. 298p.

GILBERT, Roy. Celso furtado: Economia - Resenha bibliográfica. Pesquisa $e$ Planejamento Econômico (IPEA). v.14, nº. 2, p.569-576, ago., 1984.

GUIMARÃES, Juarez. A trajetória intelectual de Celso Furtado. In: TAVARES, Maria da Conceição (org.). Celso Furtado e o Brasil. São Paulo: Perseu Abramo, 2000, p.1532 .

LIMA, Luciana Badin Pereira. Na contramão do sonho de Celso Furtado. Jornal dos Economistas. Rio de Janeiro, CORECON-RJ/SIDECON-RJ. n ${ }^{\circ}$ 214, p.12-13, mai., 2007.

NABUCO, Maria Regina. Estado e projeto nacional nas obras iniciais de Celso Furtado. In: TAVARES, Maria da Conceição (Org.). Celso Furtado e o Brasil. São Paulo: Perseu Abramo, 2000, p.59-70.

OLIVEIRA, Francisco. Um republicano exemplar. In: BRESSER-PEREIRA, Luiz Carlos; REGO, José Marcio. (Org.). A grande esperança em Celso Furtado. São Paulo: Editora 34, 2001, p.217-220.

PAULANI, Leda Maria. A utopia da nação: esperança e desalento. In: BRESSERPEREIRA, Luiz Carlos; REGO, José Marcio. (Org.). A grande esperança em Celso Furtado. São Paulo: Editora 34, 2001, p.139-156.

PRZEWORSKI, Adam. Capitalismo e social-democracia. São Paulo: Campanhia das Letras, 1989. 330p.

SANDRONI, Paulo. Novíssimo dicionário de economia. 2. ed. São Paulo: Best Seller, 1999. p. 566 